\title{
¿Qué significa filosofar? Interpretaciones sobre el objeto y la condición de la ontología de Martin Heidegger*
}

\author{
Diego Martínez Zarazúa \\ Katholieke Universiteit Leuven, Lovaina, Bélgica \\ E-mail: diego.m.zarazua@gmail.com \\ Recibido: 15 de abril de 2019 | Aprobado: 28 de octubre de 2019 \\ https://doi.org/10.17533/udea.ef.n61a06
}

Resumen: La influencia de Martin Heidegger en el medio filosófico contemporáneo es indiscutible. Sin embargo, no siempre resulta claro qué significa el que Heidegger comprenda la filosofía como una ontología, esto es, como una interrogación por el ser. Con miras a esclarecer esto, y por lo general empleando un vocabulario distinto al de Heidegger, el presente artículo ofrece la interpretación de su filosofía como una forma no positiva de investigación ontológica. Esto es, como un desarrollo de la pregunta por el ser que rechaza toda tentativa de respuesta. Para ello se analizan dos aspectos estructurales del pensamiento de Heidegger: su objeto (el ser del ente) y su condición (que haya cosa y que ésta de alguna manera se estropee).

Palabras clave: Heidegger, diferencia ontológica, ser, ente, ocultamiento, ontología, fenomenología

* El artículo fue escrito en el marco de una estancia de investigación en la Katholieke Universiteit Leuven, mientras me encontraba adscrito a la UNAM. Para tal propósito, disfruté del apoyo económico del CONACyT. Agradezco a la Dra. Pilar Gilardi (UNAM-IIH) sus valiosos comentarios al manuscrito.

Cómo citar este artículo:

Martínez Zarazúa, D. (2020). ¿Qué significa filosofar? Interpretaciones sobre el objeto y la condición de la ontología de Martin Heidegger. Estudios de Filosofía, 61, 71-90. https://doi.org/10.17533/ udea.ef.n61a06 


\title{
What does philosophizing mean? Interpretation on the object and the condition of Martin Heidegger's ontology
}

\begin{abstract}
Martin Heidegger's influence over the contemporary philosophical landscape is indisputable. However, it is not always clear what the point is in his understanding of philosophy as ontology, namely, as a question about the being. In order to clarify this, and mostly by using a vocabulary different from Heidegger's, in this paper I offer my interpretation of his philosophy as a non-positive form of ontological investigation. That is to say, as a question about the being that rejects any attempt of an answer. In order to achieve this goal, I consider two structural aspects of Heidegger's thinking: its object (the being of entities), and its condition (that there is a thing and that such a thing fails in some way).
\end{abstract}

Keywords: Heidegger, ontological difference, being, entity, concealing, ontology, phenomenology

\section{Diego Martínez Zarazúa}

Licenciado en Filosofía y Ciencias Sociales por el ITESO y Maestro en Filosofía por la UNAM (financiado en el segundo caso por CONACyT, México). Actualmente cursa el programa Research Master of Philosophy en la Katholieke Universiteit Leuven (financiado por VLUHR, Bélgica), donde también previamente realizó una estancia de investigación (CONACYT). Recientemente ha publicado "La libertad como esencia de la verdad: la relación Heidegger-Rorty" en Open Insight y "Apuntes para la crítica contextualista de la metafísica" en Xipe Totek. Su investigación actual se centra en la posibilidad de una lectura heideggeriana de Karl Marx.

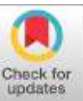


A casi un siglo de la publicación de Ser y tiempo, Martin Heidegger sigue siendo el pretexto de muchos de nosotros para escribir sobre filosofía. Pues de Heidegger nacen las más diversas posiciones y reacciones acerca del filosofar y su competencia, acerca del asunto del pensar. Y es que no es exagerado decir, aunque casi lo parezca, que gran parte de la filosofía contemporánea cobra el carácter que cobra más o menos en virtud de -o por oposición a - la extensa obra de Martin Heidegger, hoy todavía en vías de publicación. La asunción implícita de este pensamiento en los libros de Michel Foucault, la explotación del motivo hermenéutico en los de Hans-Georg Gadamer, o la controvertida pero siempre interesante interpretación de Heidegger por parte de Richard Rorty, representan sólo algunas de las razones por las cuales se justifica en general releer al "maestro de Alemania".

¿Pero qué es lo que Heidegger pretendía decir? La respuesta que dio siempre fue la misma: él estaba en el negocio de la ontología, del discurso sobre el ser. ¿Pero qué es el ser? O más precisamente, ¿qué significa el que la filosofía se interrogue sobre el ser, que haga de él su principal preocupación? Y más aún, ¿qué significa decir esto en nuestro tiempo, uno en el que se suele hablar más bien como Foucault, Gadamer, Rorty y algunos otros nos han enseñado, y menos desde aquella mistificada y vituperada jerga del ser? En este estudio quisiera aventurar una respuesta a estas preguntas.

En particular, voy a concentrarme en dos cuestiones. Si la filosofía se concibe como ontología, ¿entonces de qué se ocupa? y ¿bajo qué condiciones ocurre que se ocupe de ello? Esto es, voy intentar esclarecer el objeto de la filosofía y la condición de su emergencia. De tal manera se logrará explicar mi hipótesis de lectura del proyecto heideggeriano: éste consiste en una forma no positiva de investigación ontológica, es decir, en un desarrollo de la pregunta por el ser que rechaza toda tentativa de respuesta, sin que por ello se renuncie a reiterar la pregunta.

Mi argumento se desarrollará en cuatro etapas: empezaré por sugerir una idea provisional del quehacer de la filosofía que sirva para encarar las formulaciones de Heidegger a propósito de la ontología (1. Preliminares hermenéuticos: una idea de filosofía). Luego abordaré la cuestión del auténtico "objeto" de la filosofía (el ser), lo que a su vez me supondrá explicar qué no es su objeto (el ente) -más precisamente: qué no es su objeto último, ya que el ser siempre se dice del ente (2. No contar un mito - un mito ontoteológico). Después me detendré a explicar la condición de que la filosofía emerja, es decir, describir la circunstancia que actualiza la posibilidad de la ontología, a saber: la frustración del ser de la cosa (3. La condición de la ontología). Finalmente, remataré con algunas reiteraciones (4. A modo de conclusión).

\section{Preliminares hermenéuticos: una idea de filosofía}

Cuando uno se propone hablar de un concepto tan extenso como el de filosofía, aun si sólo es en el contexto de la obra heideggeriana, está más o menos obligado a ofrecer 
una indicación de lo que entiende por tal. Pues ciertamente una disciplina tan longeva como la nuestra difícilmente se deja traer a concepto como algo simple. Acaso porque su larga historia trajo como consecuencia el que deviniera en algo heterogéneo; acaso también porque sólo es auténticamente lo que es cuando se constituye en oposición a su tradición, es decir, en cierta oposición consigo misma. Pero esta dificultad no exime de la obligación de decir algo al respecto. En cambio, lo que sí demanda es considerar la provisionalidad de tal obligación, el reconocimiento de que definir la filosofía, aunque necesario, es irremediablemente circunstancial. Pero se ha de empezar por algún lugar, a costa de correr con este riesgo.

Eso que la filosofía hace puede expresarse por lo menos de tres formas que emplearé indistintamente, a saber, como la interrogación por la consistencia de lo que hay, por el ser del ente, o por la validez del decir. Así, detengámonos en la siguiente formulación posible: la filosofía se interroga por la validez de lo que hay. Esto significa, por un lado, que previo a la filosofía, ya hay algo, ya hay cosas. Puesto que sólo habiéndolas tiene sentido interrogarse sobre ellas. Por otro lado, también significa un respecto preciso de interrogación: de todo lo que las cosas tienen de cuestionable, la filosofía pregunta acerca de su validez (consistencia o ser), es decir, acerca de lo que confiere fundamento a que cada cosa sea la cosa que es - a que sea determinada cosa.

Así, por ejemplo, un cuestionamiento filosófico de corte epistemológico podría preguntar por aquello en que radica el que ciertas tesis sean verdaderas o falsas, mientras que uno de corte ético podría indagar en aquello por lo que determinadas maneras de conducirse son virtuosas o no. En cualquier caso queda supuesta la posibilidad de distinguir entre una y otra cosa: lo verdadero de lo falso, lo virtuoso de lo vicioso. Consiguientemente, lo que por de pronto ya hay es eso: la posibilidad de discernimiento, cualesquiera sean los criterios que en éste operen. Y la filosofía entra en juego precisamente cuando se hace cuestión de tales criterios, es decir, cuando se pregunta en qué consiste la verdad de las tesis o la virtud de las acciones. Felipe Martínez Marzoa, en cuyo modo de filosofar reposa esta exposición, explica el quehacer de la filosofía como la pretensión de "mencionar lo que siempre ya está, [las reglas del] juego que siempre ya se está jugando, aquel juego en el cual -y sólo en él- cada cosa es lo que es" (Martínez Marzoa, 2000, p. 21). Me mantendré a tono con esta descripción.

De tal modo definida la filosofía, dedicaré las secciones siguientes a esclarecer dos cuestiones desde una perspectiva heideggeriana: ¿cuál es el auténtico objeto de la filosofía? y ¿cuál es la condición de que ésta emerja? Pero antes de ponerme a ello, quiero dejar advertido el carácter de mi ejercicio como lector.

Es bien cierto que ya en el solo reconocimiento de algo como una lectura, se ha dejado de admitir la univocidad de la intelección para dar cabida a interpretaciones equívocas. Con todo, al leer todavía se podría conservar la pretensión -muy legítima- de reportar sistemáticamente el pensamiento de alguien; o en cambio, de renunciar a ello y acometerse a una exégesis más bien ecléctica, sin embargo motivada por inquietudes 
concretas. Yo he renunciado a lo primero por razón de lo segundo: sacrifico una lectura sistemática en aras de una interesada. Y no porque una excluya a la otra, sino porque para ganar en ambas se requiere de un genio que echo en falta. Lo que quiere decir que mis lecturas presentarán cierto grado de deslealtad con respecto al texto. No sobra decir que este estilo de exégesis jamás fue lejano a Heidegger. Ni tampoco que actuar conforme a una absoluta fidelidad, conduciría al absurdo resultado de aquel cuento de J. L. Borges en que los cartógrafos elaboraron un mapa que tenía el tamaño del Imperio y coincidía puntualmente con él. Con todo, las fuentes originales seguirán ahí.

\section{No contar un mito —un mito ontoteológico}

Mi hipótesis de trabajo es que en Heidegger puede leerse el esfuerzo de plantear una forma no positiva de investigación ontológica, o sea, un desarrollo de la pregunta por el ser que estropea toda tentativa de respuesta, porque toda respuesta es diferente de aquello por lo que se pregunta. ${ }^{1}$ En el fondo, esto se piensa en atención a la diferencia ontológica, la diferencia entre el ser y el ente en la que Heidegger reiteradamente se obstinó.

Pero cabe preguntarse cuál es el significado de la diferencia ontológica, más allá de que miente la irreductibilidad del ser al ente. En su libro Los caminos de Heidegger, Hans-Georg Gadamer escribió:

Al recordar las primeras lecciones de Heidegger a las que asistí en 1923 en Friburgo y en 1924 en Marburgo, me viene a la mente que entonces la expresión "diferencia ontológica" era como una palabra mágica. Siempre volvió a aparecer con todo el énfasis con el que un pensador concentrado hacía sentir que aquí estaba apuntando a algo muy decisivo, aunque no expresara realmente en palabras los detalles de las conexiones y el significado de lo que quería decir. Era casi como otra expresión corriente cualquiera, con la que nos desechaba a menudo cuando tratábamos de exponer nuestros propios pequeños intentos de

1 Esta hipótesis de interpretación encuentra su impulso en un cierto proyecto de lectura que encabezan principalmente Felipe Martínez Marzoa y Arturo Leyte. Aparte del proyecto específico que abren ellos dos, aunque igualmente preocupados por el asunto de la negatividad y la filosofía heideggeriana, cabe mencionar los trabajos de Santiago Chame (2017) y David R. Law (2000). Aun así, no sobra insistir en que la posibilidad misma de este proyecto hermenéutico anida ya en la obra de Heidegger. Una de sus formulaciones más explíitas puede encontrarse en la Introducción y la Segunda Parte de Los problemas fundamentales de la fenomenología. En la Introducción, Heidegger advierte: "La filosofía no se relaciona de forma positiva, ponente, con el ente, en tanto que tal o cual. ¿Cabe justificar la presuposición de que la filosofía, a diferencia de las ciencias, no se relaciona positivamente con el ente? ¿De qué ha de ocuparse la filosofía si no es con el ente, con aquello que es, así como también con la totalidad de lo que es? Lo que no es, claro está que es la nada. ¿Debe la filosofía, como ciencia absoluta, tener como tema la nada?" (Heidegger, 2000, p. 35). Sobre la relación de la filosofía con el ente y la nada habremos de volver repetidas veces en este trabajo. Que por lo pronto baste con decir que si toda respuesta es diferente de aquello por lo que se pregunta, es porque toda respuesta es propositiva, es decir, en un cierto sentido óntica, mientras que lo inquirido por la filosofía es siempre el ser. 
pensar y contribuciones. Heidegger decía entonces: "Sí, sí; pero esto es óntico y no ontológico" (Gadamer, 2003, p. 355).

¿Y es que qué significa la diferencia ontológica? ¿Cuáles son, en efecto, "los detalles de las conexiones y el significado de lo que quería decir"? Esa expresión, que como tal sólo aparece hasta 1927 en Los problemas fundamentales de la fenomenología (Adrián Escudero, 2009, p. 135), informa, sin embargo, la filosofía entera de Heidegger, desde su pensamiento temprano hasta el tardío. Por eso no hace falta decir que Ser y tiempo supone en todo momento la diferencia ontológica. Examinemos cómo la introduce Heidegger.

Ser y tiempo lleva por epígrafe la confesión platónica de una perplejidad: "Porque manifiestamente vosotros estáis familiarizados desde hace mucho tiempo con lo que propiamente queréis decir cuando usáis la expresión 'ente'; en cambio, nosotros creíamos otrora comprenderlo, pero ahora nos encontramos en aporía" (Heidegger, 2012, p. 21. Original en Platón, 1988, 244a). ${ }^{2}$ El diálogo del que se toma el texto citado, El Sofista (o Del Ser), contiene otro pasaje del que Heidegger también recupera algo: "Me da la impresión de que cada uno de ellos [Parménides y aquellos otros antiguos que hablaron del 'ente'] nos cuenta una especie de mito" (Platón, 1988, 242c. Traducción modificada).

Con estas referencias a Platón, Heidegger pone en consideración dos cuestiones distintas pero relativas: que aquello de lo que no sospechábamos guardar dudas se ha vuelto cuestionable; y que los más antiguos pronunciamientos han contado un mito. Mejor cabría decir: porque sólo han contado mitos sobre el ser, cabe albergar sospechas acerca de tales pronunciamientos. Por eso al comienzo de Ser y tiempo aparece la siguiente indicación fundamental:

El ser del ente no "es", él mismo, un ente. El primer paso filosófico en la comprensión del problema del ser consiste en no mython tina diēgeisthai, en "no contar un mito", es decir, en no determinar el ente en cuanto ente derivándolo de otro ente, como si el ser tuviese el carácter de un posible ente (Heidegger, 2012, p. 27).

Contar un mito acerca del ser, a ojos de Heidegger, en realidad significa contarlo sobre los entes, y por consiguiente no trata en absoluto del ser. ¿Entonces de qué trata?

A treinta años de la publicación de Ser y tiempo, treinta años de un pensar itinerante, Heidegger dicta una conferencia que, sin embargo, permite aclarar lo que significa contar un mito en el más importante de sus primeros escritos. La conferencia que dicta en 1957 lleva un título ya de suyo ilustrativo: La constitución onto-teo-lógica de la metafísica. Y es que, aunque sea diacrónicamente posterior a Ser y tiempo, sincrónicamente está

2 Nótese que en griego antiguo tò ón significó con ambigüedad lo que en lengua moderna puede -y heideggerianamente debedistinguirse, por un lado, como "ente" o "lo que es", y por el otro, como "ser" (Cf. n. del trad. en Platón, 1988, p. 384). Entonces, uno podría preguntarse con qué significado leer el extracto citado. Pero más que ofrecer alguna indicación filológica, lo filosóficamente relevante está en señalar que precisamente en no haberse notado la ambigüedad, reside el que se "cuente un mito". 
concentrada en uno de sus motivos fundamentales: mostrar que el ser, en cuanto principio, no es un ente. Por eso se justifica recurrir por un momento a esa conferencia antes de regresar a la órbita de Ser y tiempo. El pasaje más revelador es el que sigue:

[Para la metafísica] el asunto del pensar es lo ente en cuanto tal, es decir, el ser. Éste se manifiesta en el modo esencial del fundamento. Según esto, el asunto del pensar, el ser en cuanto fundamento, sólo es pensado a fondo cuando el fundamento es representado como el primer fundamento, "proté arché". El asunto originario del pensar se presenta como la cosa originaria, como la causa prima, que corresponde al retorno fundamentador a la ultima ratio, a la última cuenta que hay que rendir. El ser de lo ente sólo se representa a fondo, en el sentido del fundamento, como causa sui. Con ello, ha quedado nombrado el concepto metafísico de Dios. La metafísica debe pensar más allá hasta llegar a Dios, porque el asunto del pensar es el ser, pero éste se manifiesta de múltiples maneras en tanto que fundamento: como lógos, como hypokeimenon, como sustancia y como sujeto (Heidegger, 1988, p. 131).

Así, la metafísica ${ }^{3}$ se constituye onto-teo-lógicamente toda vez que piensa el fundamento del ente en términos del ente máximo: sea proté arché, causa prima, summum ens, etc. Aquí se debe precisar que el "error" de la metafísica no radica en la presuposición de un fundamento, sino en el modo de comprenderlo y caracterizarlo. Pues el ente mismo ya supone su estar fundamentado, su ser lo que es. Veamos por qué.

Es un hecho que toda cosa comparece como esto o lo otro, como algo determinado. También lo es que toda cosa siempre se distingue de lo demás por razón de ser lo que ella misma es. Y es que se distingue o determina, digámoslo así, en virtud del límite que le es propio. Límite por razón del cual hay cosa concreta, cosa delimitada; en suma: por el cual se es cosa -ésta y no otra. Con esto debe quedar claro que la noción de límite (ser) es inherente a la de cosa (ente). Por lo pronto esta descripción no exige pronunciarse acerca de en qué consiste el límite (i.e. en qué consiste ser). Basta limitarse a que ello acontece. Así, el análisis deja de lado cuestiones ulteriores como la de si el límite adviene de "más allá" o "más acá" de las cosas. Fenomenológicamente hablando,

3 Ciertamente, el término metafísica sólo cobra un lugar preponderante en el pensar heideggeriano luego de la lección sostenida en 1929, ¿Qué es metafísica?, y decididamente en el curso del semestre de invierno 1929-1930, Los conceptos fundamentales de la metafísica. En ambos textos se da a entender que metafísica es nombre de la filosofía: "Metafísica como filosofar, como nuestro propio filosofar, como hacer humano" (Heidegger, 2007b, p. 27). "La metafísica es el preguntar más allá de lo ente a fin de volver a recuperarlo en cuanto tal y en su totalidad para el concepto. [...] El ir más allá de lo ente ocurre en la esencia del Dasein. Pero es que este ir más allá es la propia metafísica. Es eso lo que explica y determina el que la metafísica forme parte de la 'naturaleza del hombre'. No es ni una disciplina de la filosofía académica ni el ámbito de ocurrencias arbitrarias. La metafísica es el acontecimiento fundamental del Dasein. Es el Dasein mismo" (Heidegger, 2007a, pp. 106-107). Debido a los propósitos de este trabajo, no cabe que me detenga en explorar el conjunto de razones que lleva a Heidegger a modificar su vocabulario en la travesía que significa su pensamiento. No obstante, me considero por lo menos obligado a reconocer las licencias interpretativas que me estoy permitiendo al "saltar" de uno a otro periodo de su pensamiento. 
resulta suficiente con notar que la noción de límite -cual sea- es inmanente al haber de la cosa.

Así pues, que hay fundamento no es algo que se postule acerca de las cosas, sino lo ineludiblemente presupuesto en que se reconozca cosa determinada y distinta. Y si persistimos únicamente en lo así descrito, resulta cuestión aparte la de qué cosa sea el fundamento, es decir, la de cómo quepa caracterizarlo - si acaso cabe caracterizarlo. Sin embargo, la metafísica da este "salto" que de suyo la descripción no exige, y a la pregunta por el fundamento, por el ser, se responde con el summum ens, con el máximo ente. Arturo Leyte explica que tal respuesta es óntica (y quizá esta explicación habría satisfecho al joven Gadamer) porque a la pregunta por el ser se responde:

el ser, es... esto, lo otro, o lo de más allá. [...] En todos estos casos (y en cualquier otra 'definición' que se pueda ofrecer), estamos contestando con algo determinado, con lo que Heidegger diría que es un ente. Pero un ente es algo que es, y no el ser (estudio previo en Heidegger, 1988, pp. 13-14).

Por eso Heidegger acusa a la tradición no sólo de haber omitido investigar el ser, sino también de haber obstruido el planteamiento de la pregunta propiamente ontológica (Cf. Heidegger, 2012, p. 25). ${ }^{4}$ Y es que, en efecto, de seguir a Heidegger, ¿cómo habría cabido plantear la pregunta por el ser, cuando al ser la metafísica lo representó como el ente máximo, ente del que se deriva, como dice en Ser y tiempo, la determinación del resto de los entes? Por eso Alejandro Vigo explica que la ontoteología, entendida como un retroceso óntico hasta el ser comprendido como causa primera (aunque así se lo malcomprenda por completo), "trae consigo una tendencial nivelación de la diferencia entre ser y ente, y, con ello, acarrea también un oscurecimiento de la propia pregunta por el ser, en su sentido más propio" (Vigo, 2008, p. 139). Así, si contar un mito significa determinar el ente en cuanto ente derivándolo de otro ente, entonces la constitución ontoteológica de la metafísica equivale a una constitución mítica.

Heidegger está empeñado en señalar la diferencia entre el ser (la consistencia, la validez) y el ente (lo que hay, lo que se dice), porque en la discusión alemana de finales del siglo XIX y principios del XX se pensaba el problema de la filosofía fundamentalmente de dos maneras. Por un lado, hubo aquellos que, impulsados por los excesos especulativos de la metafísica moderna, asumieron que la validez se constituye a través de regularidades contingentes del más acá (ora de los procesos psíquicos,

4 En el §1 de Ser y tiempo, Heidegger expone tres prejuicios que han obstruido el planteamiento de la pregunta por el ser: 1. el ser es el concepto más universal, y por ende 2. es indefinible, puesto que toda definición requiere de género y diferencia; 3 . además, es un concepto evidente por sí mismo, y que cualquiera comprende expresiones como "el cielo es azul" o "soy feliz". Concluye diciendo que: "La consideración de los prejuicios nos ha hecho ver que no sólo falta la respuesta a la pregunta por el ser, sino que incluso la pregunta misma es oscura y carece de dirección. Por consiguiente, repetir la pregunta por el ser significa: elaborar [...] el planteamiento mismo de la pregunta" (Heidegger, 2012, p. 25). A estos tres prejuicios quizá cabría agregar esto que se viene diciendo sobre la nivelación de la diferencia ontológica que obstruye un auténtico preguntar por el ser. 
como fuera el caso del psicologismo de Benno Erdmann; ora del momento histórico, como fuera el caso del historicismo de Wilhelm Dilthey), ${ }^{5}$ y por lo tanto no admitieron, a riesgo de dogmatismos, el establecimiento de legalidades perennes. Por otro lado, hubo quienes incómodos con el relativismo resultante del primer procedimiento, defendieron la posición opuesta e insistieron en salvar la perennidad del orden legal en el más allá, en el topos huperouranios (como fuera el caso de Rudolf H. Lotze [Cf. 1884, pp. 433-449]).

El problema para Heidegger es que en cualquiera de estas posiciones se contesta a la pregunta ontológica con algo determinado: sea la psicología empírica, la conciencia histórica o los valores platónico-lotzianos. Y según se ha dicho, determinado es lo ente, no el ser. Pero entonces, planteada en estos términos, la discusión conduce a una aporía con respecto a la cuestión ontológica. Pues resulta que todo responder al qué del fundamento contribuye, a ojos de Heidegger, a la constitución ontoteológica de la metafísica y, en consecuencia, al olvido del ser y la trivialización de su pregunta.

Leyte advierte bien este problema. Los unos plantean que el ser viene de más allá, donde la verdad y el bien son los únicos soberanos; aunque así visto, el ámbito no deja de ser óntico, por privilegiado que sea. Los otros plantean la imagen opuesta, según la cual todo pertenece a este "más acá" porque no hay "más allá" alguno:

En realidad, no se trata ni de más acá ni de más allá, al modo en que el platonismo habló de dos mundos. Haber, por haber, sólo hay entes [...]. Pero eso no quita [...] que precisamente porque todo lo que es resulta ser ente, el "es" propiamente dicho no sea tal ente. En definitiva, todo es ente y en ese "es", que se juega fuera del todo, reside la diferencia" (Leyte, 2005, p. 82).

Y es que el verdadero extravío no consiste en que, dentro de esta dualidad entre más allá y más acá, uno u otro lado detente la verdad de su contrario. A la hora de aclarar estas posiciones, escribe Heidegger, "se trata no tanto de dejar las cosas claras entre ellas ni de decidir cuál de ellas sea la solución, sino de llegar a ver que las dos se sostienen sólo sobre la base de una omisión" (Heidegger, 2006, p. 278), a saber, del ser en cuanto tal.

¿Entonces cómo enfrentar la aporía? Si una u otra posición se extraviaron de camino a la cuestión ontológica, fue por responder al qué de la pregunta del ser con un ente. Pero ente es todo posible contenido de referencia. ¿No será más bien que el auténtico error es haber respondido en primer lugar? Pues con respecto a la cuestión ontológica, nada es alternativa como respuesta. Y en efecto, la nada debe ser la respuesta. ¿Mas cómo así que de camino al ser ahora tropecemos con la nada? Y sin embargo, Platón

5 La lógica psicologista de Benno Erdmann fue comentada críticamente por Husserl (Cf. 1999, §40) y Heidegger (Cf. 2004, §6). Tanto el historicismo de Dilthey (2000) como el proyecto neokantiano naturalista fueron brillantemente discutidos por Husserl en La filosofía, ciencia rigurosa. 
ya lo había expuesto en El Sofista (mismo diálogo que Heidegger cita al inicio de Ser y tiempo): dado que el ser y la nada comparten la dificultad de ser irreductibles al modo de ser de las cosas, "nos queda la esperanza de que cuando uno de ellos se muestre, ya sea oscura, ya sea claramente, también el otro se mostrará" (Platón, 1988, 250e-251a).

A pesar de haber sido tratada con brevedad en el $\$ 40$ de Ser y tiempo, la nada reaparece como objeto temático eminente en una lección redactada en $1928^{6}$ (aunque sostenida en 1929): ¿Qué es metafísica? Ya sólo la cercanía cronológica de ambos textos da para pensar que debe haber continuidades entre uno y otro objeto temático -el ser y la nada-, y que las diferencias entre una y otra investigación al cabo deberán ser destacadas sobre el trasfondo de tales continuidades. Y es que pronto llama la atención que se trate la cuestión de la nada de manera casi paralela a como se trató la cuestión del ser. Por ejemplo: las dificultades que entraña el preguntar por uno u otra, de modo que la pregunta misma no encubra aquello que interroga ( $C f$. Heidegger, 2012, §§1-2; 2007a, pp. 96-98). O que la esencia de la nada es el desistimiento, de la misma manera que ocultarse es propio del ser (Cf. Heidegger, 2012, §7-C; 2007a, p. 101). O también que en su desistir u ocultarse, la nada o el ser remiten a lo ente; y más aún, hacen posible el carácter manifiesto de lo ente (Cf. Heidegger, 2012, §7-C; 2007a, p. 102).?

Al notar todas estas semejanzas uno no puede evitar preguntarse: ¿a qué responde que, para dirigirse al mismo asunto, a un año de Ser y tiempo Heidegger haya cambiado de términos? Para explicarnos esto, sigo a William Blattner en que el recurso heideggeriano a la nada en ¿Qué es metafísica? (1929) y posteriores desarrollos (p. ej. el Epílogo [1943] y la Introducción [1949] a ese texto), se debe a la reticencia de decir algo "disciplinado, científico, teorético-conceptual" ("disciplined, wissenschaftlich, theoretic-conceptual") a propósito del ser (Blattner, 2007, p. 26). ${ }^{8}$

$Y$ es que el nombre "ser" significa el fundamento de la quididad -del ineludible qué de cada cosa. No de este o aquel contenido de referencia, sino de la quididad en cuanto tal. Y si de acuerdo a la diferencia ontológica el ser no es un ente, luego el ser tampoco es un contenido de referencia, una quididad. De ahí que la mejor manera de referir al ser sea no a través de la adjudicación de contenidos, sino de la ausencia

6 Las fechas las hace notar el propio Heidegger en el prólogo a la tercera edición del texto De la esencia del fundamento (Cf. Heidegger, 2007a, p. 109).

7 Agradezco a Pilar Gilardi por haberme hecho notar esto en su Heidegger: la pregunta por los estados de ánimo (1927-1930). Por ejemplo, cuando explica que "La denuncia sobre el olvido del ser al inicio de Ser y tiempo se traduce en ¿Qué es metafísica? como olvido de la nada. Lo que se pone de manifiesto en este último texto es que no abordar el problema de la nada, en realidad significa no abordar el problema del ser; quedarse exclusivamente en el ámbito de lo ente" (Gilardi, 2013, p. 172).

8 Donde sin embargo mantengo ciertas reservas, es con respecto a su opinión de que el recurso a la nada es una medida desesperada que negocia entre la ontología científica de Ser y tiempo (según Blattner, en algún sentido todavía positiva), y la posterior visión poética del discurso sobre el ser que emerge en la década de 1930 (Cf. Blattner, 2007, p. 26). Mis reservas se deben mi manera de leer Ser y tiempo como un proyecto en conformidad con la diferencia ontológica. Por este motivo, la idea de que Heidegger va en búsqueda de una ontología científica, entendida como discurso positivo (temático, óntico) sobre el ser, debe rechazarse ya incluso desde la obra de 1927 — a pesar de que la propia fraseología heideggeriana a veces resulte poco afortunada. 
de tales, ausencia que mienta la noción heideggeriana de la nada. Así, Heidegger dirá en el Epílogo a ¿Qué es metafísica? que "la nada, como lo otro de lo ente, es el velo del ser" (Heidegger, 2007a, p. 258) porque, "a diferencia de lo ente, el ser no se deja representar y producir como un objeto. Eso absolutamente otro, en comparación con lo ente es lo no-ente" (Heidegger, 2007a, p. 253).

Por eso es que, si como dice Blattner, la exploración de nuevas formas de expresarse responde a la reticencia de decir algo "disciplinado, científico, teoréticoconceptual" a propósito del ser, entonces tampoco deberá trivializarse el hecho de que el problema fundamental de Ser y tiempo esté formulado como una pregunta (Seinsfrage), y no como una tesis. ${ }^{9} \mathrm{Y}$ es que a la hora de leer a Heidegger debe tenerse presente que está en juego el planteamiento de una forma no positiva de investigación ontológica. Esto es, de una forma de inquirir por el ser que soslaye todo modo pro-positivo. ${ }^{10}$ Después de todo, quien pregunta no afirma, puesto que pregunta. Así lo concluyeron Sócrates y Alcibíades, cuando el joven le achacó a su maestro tener una opinión:

Sóc. - ¡Y bien!... en una palabra, en una conversación de preguntas y respuestas, ¿quién afirma una cosa? ¿el que pregunta o el que responde?

Alci. - Me parece, Sócrates, que el que responde.

Sóc. - ¿Y hasta ahora no soy yo el que ha preguntado?

Alci. - Sí.

Sóc. - ¿Y no eres tú el que me ha respondido?

Alci. - Seguramente.

Sóc. - ¿Quién de los dos ha sido, tú o yo, el que ha afirmado todo lo que hemos dicho? Alci. - Tengo que convenir en que yo. [...]

Sóc. - Se te puede aplicar, Alcibíades, este dicho de Eurípides: tú eres el que ha nombrado, porque no soy yo el que lo he dicho, sino tú; y no tienes motivo para achacármelo (Platón, 1871, pp. 139-140).

9 Esta estrategia se prolonga, por lo menos, hasta la época de sus cursos sobre Nietzsche: las comunicaciones del pensamiento de los pensamientos se dan en forma de pregunta, y no como exposición doctrinal (Cf. Heidegger, 2002, p. 265).

10 El término "positivo" deriva del latín positus, que a su vez proviene de la voz griega thesis. En el contexto heideggeriano, el término "positivo" mantiene una permanente trabazón con lo óntico. De ahí que incluso se los llegue a emplear como sinónimos: "[...] todas las ciencias no filosóficas tienen como meta el ente, y ciertamente, de tal manera, que éste se les presenta de antemano siempre como ente. Lo presuponen, es para ellas un positum. Toda proposición de las ciencias no filosóficas, también las de las matemáticas, son proposiciones positivas. Por ello decimos que todas las ciencias no filosóficas, a diferencia de la filosofía, son ciencias positivas [0 sea, ciencias ónticas]" (Heidegger, 2000, p. 38). En cambio, la filosofía, que es ontología, es por lo tanto no-positiva; o lo que es lo mismo, pero al hilo de la etimología griega: es a-tética. De ahí la importancia del callar en varios de los textos heideggerianos, p. ej. en Ser y tiempo (§34), y de modo más destacado en sus reflexiones sobre la sigética en los Aportes a la filosofía.

Dicho sea de paso, libros como Las palabras y las cosas y La arqueología del saber atestiguan el alto rendimiento que Michel Foucault sacó del término "positivo" y sus derivados, con el señalado sentido heideggeriano. 
En resumidas cuentas, en esta sección me he ocupado de elucidar el "objeto" -si se quiere, auténtico- de la ontología heideggeriana: el ser, a diferencia del ente. Ello me llevó a exponer la exigencia de "autentificar" tal objeto al hilo de la indicación platónica de "no contar un mito", que relacioné con la noción heideggeriana de ontoteología. Luego constaté que para la pregunta ontológica no hay respuesta que cumpla con las exigencias de su objeto. En consecuencia, nada debe ser la respuesta. Fue entonces que concluí que el recurso a la nada, y también al preguntar, contribuyen a una lectura del proyecto heideggeriano como una forma no positiva de investigación ontológica.

\section{La condición de la ontología}

Se ha visto que la ontología pregunta por el ser, ¿pero bajo qué condiciones emerge este cuestionar? Según expondré, hay dos exigencias estructurales para la emergencia de la ontología: en primer lugar, que haya cosa, y en segundo, que ésta se torne problemática. Empezaré por lo primero.

Hay que insistir nuevamente en que la cosa es de suyo determinada, y lo que en ello siempre ya anida: la posibilidad de un desarrollo filosófico. Según fue expuesto, en el haber de cada cosa se esconde la aplicación de algún criterio -cual sea, pero siempre alguno- de determinación o distinción, contraconceptos que en definitiva refieren a un límite. Límite en virtud del cual determinada cosa consiste en esto y no en aquello, y por cuya razón decimos de la cosa lo que en efecto cabe ser dicho; o sea, hay para determinada cosa expresiones judicativas legítimas e inadmisibles. De esta manera se mienta eso que en el vocabulario de Ser y tiempo se dice como que el ser es "aquello que determina al ente en cuanto ente, eso con vistas a lo cual el ente, en cualquier forma que se lo considere, ya es comprendido siempre" (Heidegger, 2012, p. 27). Si el límite es aquello en virtud de lo cual hay determinación, entonces el límite mienta lo mismo que ser.

Ahora bien, no sobra señalar que en esta exposición la noción de ser o de límite no constituye ningún agregado al ente o a la cosa. Hay, es verdad, el reconocimiento de una distinción entre cosa y límite, entre ente y ser, o en sus formas adjetivas, entre lo óntico y lo ontológico. Pero es preciso insistir en que no se llega a ese reconocimiento por medio de la yuxtaposición de dos formas diferentes de haber, "al modo en que el platonismo habló de dos mundos". Introducir alguna suerte de dicotomía platonista, escribe Heidegger, equivale a tergiversar el problema "ya en su planteamiento inicial, en la separación -no aclarada ontológicamente- de lo real y lo ideal" (Heidegger, 2012, p. 233). En lugar de esto, hay que comprender que "el ser se encuentra en el hecho de que algo es y en su ser-así, [...] en el estar ahí, en la consistencia, en la validez, [...] en el 'hay'” (Heidegger, 2012, p. 27). Así que sólo ahí, en la consistencia, en el haber, y en ninguna otra instancia (porque no hay otra instancia), debe reconocerse la susodicha diferencia. El desdoblamiento debe ser interno, ha de acontecer en la 
cosa misma. Y así lo es según he procurado mostrar: puesto que la cosa es de suyo determinada y distinta, puesto que siempre es esto o aquello y no lo otro, le resulta inherente la noción de un límite, esto es, le resulta inherente ser.

Así, el desarrollo de la cuestión ontológica consiste en la exhibición de aquello que mora en el ente constituyendo "su sentido y fundamento" (Heidegger, 2012, p. 55). Tal es la pregunta por el ser. Pero como el "ser es siempre el ser de un ente" (Heidegger, 2012, p. 30), y "el ser constituye lo puesto en cuestión, [...] tendremos que lo interrogado en la pregunta por el ser es el ente mismo. El ente será interrogado, por así decirlo, respecto de su ser" (Heidegger, 2012, p. 27). Es decir, la pregunta del ser será siempre la pregunta del ser del ente; la ontología sólo será posible en referencia a lo óntico. De ahí que Heidegger escribiese que tal preguntar no es "una pura especulación en el aire sobre las más universales generalidades", sino que por arrancarse de las cosas mismas, es "la pregunta más fundamental y a la vez la más concreta" (Heidegger, 2012, p. 30).

Pero así como el ser siempre es el ser de lo ente, ente sólo hay por mor de su ser. Esto significa que dado que hay cosa, entonces su ser "ya debe estar de alguna manera a nuestra disposición" (Heidegger, 2012, p. 26). Por eso la comprensión del ser, aunque mediana y vaga, es un factum (Cf. Heidegger, 2012, p. 26). Y sólo desde ahí, desde la vaga pero efectiva comprensión del ser del ente, puede "brotar la pregunta explícita por el sentido del ser y la tendencia a su concepto" (Heidegger, 2012, p. 26), o sea, arrancar un desarrollo ontológico.

Resulta, pues, que sólo desde la comprensión del ser del ente, sólo porque reconocer la cosa significa reconocer que hay determinación, que no hay indefinición ( $C f$. Martínez Marzoa, 1999, p. 9), esto es, que hay en definitiva un límite, es que puede haber filosofía. Sin embargo, y por así decirlo, con esto sólo se ha expresado la primera condición de que haya filosofía. Falta todavía entender cuándo emerge ésta; por qué ocurre que se interrogue al ente respecto de su ser; qué actualiza la posibilidad de la pregunta ontológica. Estas interrogantes no son accesorias a la cuestión filosófica, sino constitutivas, al menos con respecto al pensamiento de Heidegger. Pues según es mi interpretación, en que se pase del operativo estado preontológico (del que la cosa sea) a la investigación ontológica explicitante (al qué es la cosa), sobreviene aquel recurrente motivo de la ontología heideggeriana, referido por una variedad de términos como el olvido, pérdida, desistimiento, ocultamiento, etc., del ser.

Por mor del argumento que voy a presentar, recuerdo al lector la expresión habitual con que Martínez Marzoa describe el quehacer de la filosofía: "mencionar lo que siempre ya está, [las reglas del] juego que siempre ya se está jugando, aquel juego en el cual -y sólo en él-cada cosa es lo que es" (Martínez Marzoa, 2000, p. 21). Según creo, con la metáfora del juego que siempre ya se está jugando se incrementa el rendimiento de un tema de importancia relativa en Ser y tiempo, a saber, la condición respectiva y la significatividad como constitutivas de la mundaneidad del mundo (Cf. Heidegger, 2012, §18). La virtud de aquella formulación es que permite encarar la pregunta antes planteada sobre la condición de la emergencia de la filosofía entendida como ontología. 
Así pues, al hilo del motivo heideggeriano de la pragmaticidad, luego potenciado por la metáfora del juego que siempre ya se está jugando, cabrá abordar la pregunta por aquello que actualiza la posibilidad de la cuestión ontológica, esto es, la explicitación de la segunda de las condiciones bajo las cuales hay filosofía.

En los §§14-18 de Ser y tiempo Heidegger se encarga de elucidar el fenómeno del habérselas pragmáticamente con el ente, es decir, el trato con los útiles (Zeug). Heidegger expone que al martillar (ejemplo ya clásico) no se aprehende temáticamente el martillo

como una cosa que se hace presente para nosotros, ni [se] sabe en absoluto de la estructura pragmática en cuanto tal. [...] Cuanto menos sólo se contemple la cosamartillo, cuanto mejor se eche mano del martillo usándolo, tanto más originaria será la relación con él, tanto más desveladamente comparecerá como lo que es, como útil. [...] Lo a la mano no es conocido teoréticamente ni es primeramente temático ni siquiera para la circunspección. Lo peculiar de lo inmediatamente a la mano consiste en retirarse, por así decirlo "a" su estar a la mano para estar con propiedad a la mano (Heidegger, 2012, p. 91).

Así, en su trato efectivo el útil acontece estando respecto a la obra que sirve, en relación a otros útiles, etc., pero siempre de manera irrelevante. De ahí que sea dado decir que, siendo verdaderamente útil, el ente no acontece como tal, no es patente, no destaca ni "llama la atención", sino que meramente se emplea. La empleabilidad, pues, de alguna manera supone que el ente caiga fuera de la mirada temática. Es no siendo visible como el martillo logra ser en verdad el útil que es. De tal manera se pone de relieve, por lo pronto en el ámbito de la pragmaticidad, que para que la cosa sea en verdad, debe ser imperceptible, debe -en cierto sentido- dejar de ser.

Ahora bien, Heidegger continúa preguntándose si acaso hay alguna manera de acusar el silencioso estar-vuelto del útil hacia otros útiles, o sea, si acaso es posible patentar la condición respectiva. Y sí que lo es, pero sólo a costa de interrumpirla. Fallando es como el martillo deviene temático. En verse impedido el trato para emplear el martillo con respecto a... (el clavo, la madera, la obra, etc.), se acusa la previa condición respectiva presupuesta en el trato mismo. Pero ello, insisto, sólo a expensas de perder la remisión. Y si antes se ha dicho que el ser del útil es fundamentalmente su estar remitido, acusarlo en su ser equivale a perderlo -aunque por lo pronto sea perderlo en cuanto útil... ¿y sin embargo no es esto ya perderlo del todo?

Sin sobreestimar todavía el alcance de esta pérdida, nótese que desde el §9 de Ser y tiempo Heidegger ya se había dejado escrito que para los antiguos:

La previa referencia al ser en todo hablar (lógos) que dice del ente es el kategoreisthai. Esta palabra significa, por lo pronto, acusar públicamente, decirle a alguien algo en la cara delante de todos. En su uso ontológico, el término quiere decir algo así como decirle al ente en su cara lo que él es ya siempre como ente, es decir, hacerlo ver a todos en su ser (Heidegger, 2012, p. 66). 
¿Acaso no se anticipa ya de alguna manera que si lo que se pretende es acusar públicamente al ente en su ser, la acusación devendrá en su pérdida, ya no sólo del útil, sino del ser del ente en cuanto tal? Todavía no cabe más que bosquejar este posible desenlace, que por lo pronto sólo dejo indicado.

Así pues, recuerdo al lector la pregunta conductora: ¿bajo qué condiciones hay la filosofía? Se ha dicho que su surgimiento supone que la cosa sea; mas no sólo eso, sino también que se torne problemática, es decir, que de alguna manera la cosa deje de ser. En Identidad y diferencia, Heidegger compara esta segunda condición con la de un litigio. Un litigio, sin embargo, que el pensar no provoca. "El asunto del pensar es lo que un litigio tiene en sí de litigioso. [...] El asunto del pensar apremia al pensar hasta llevarlo a su asunto y desde éste a sí mismo" (Heidegger, 1988, p. 99).

Lo que en Identidad y diferencia se dice como que el asunto del pensar es de suyo un litigio apremiante, aquí se ha dicho como que, para que haya filosofía, la cosa precisa tornarse problemática o en cierto sentido dejar de ser, pero porque algo en ella se ha frustrado y es entonces que nos interpela saliendo de su silencio. Pues la cosa es cierta, en verdad, cuando no se tematiza (Cf. Martínez Marzoa, 1999, p. 14). Cuanto menos se lo contemple, decía con Heidegger, cuanto mejor se eche mano del martillo, tanto más desveladamente comparecerá como lo que es. Por eso la inempleabilidad del martillo es exigida para la llamatividad de la condición respectiva. O según la metáfora de Martínez Marzoa, el juego sólo se visibiliza cuando a su vez se interrumpe:

si hemos dicho que la detención [del juego] es inherente a que el juego sea relevante, entonces lo que estamos diciendo es que la detención, por muy excepcional que sea y por más que signifique la pérdida, [...] es con todo ello exigida, requerida, pues lo que en ningún modo -ni siquiera excepcionalmente-comparece o es relevante, eso sencillamente no acontece (Martínez Marzoa, 1999, p. 14).

Así, la filosofía se abre paso sólo en esa ambigua situación consistente, por un lado, en que la cosa sea, es decir, sea temática, y por el otro, en que la cosa deje de ser, puesto que la tematicidad ocurre a costa de la interrupción del "juego en el cual -y sólo en él- cada cosa es lo que es". Con todo, entiéndase que no se trata de un doble significado de la palabra "ser", a saber: por un lado, en cuanto el carácter de lo tematizado, de lo que acontece, y por el otro, en cuanto la efectiva operatividad, que por no ser relevante "sencillamente no acontece". Más bien resulta que

el único significado de esa palabra está justamente en la bisagra -en el doblezde eso de que la relevancia es la pérdida, de que [...] el juego tiene lugar en cuanto que a la vez se esfuma. En otras palabras: "ser" significa siempre a la vez e inseparablemente "ser" y aquello en que "ser" siempre ya ha quedado atrás (Martínez Marzoa, 1999, pp. 14-15). 
Este doblez no es de ninguna manera ajeno a Heidegger - es justamente Heidegger. Ya lo acusaba en Ser y tiempo al decir que, modernamente, substantia se empleó para referirse "tanto al ser del ente que es sustancia, vale decir, la sustancialidad, como el ente mismo: una sustancia". Y de manera refleja, en Grecia tò ón significó "1. lo ente (el estar siendo), 2. los entes". La ambigüedad, además anota, "no es casual" (Heidegger, 2012, p. 111).

Cabe concluir esta sección señalando el modo en que estas reflexiones afectan el vínculo de la filosofía con otro tipo de discursos. Esto que he venido diciendo, que se filosofa sobre la frustración de la cosa, o que el asunto del pensar es litigioso, impacta directamente sobre la relación interna que la filosofía, en tanto desarrollo de la cuestión ontológica, guarda con las formas del decir propiamente ónticas.

Hay una gran variedad de desarrollos discursivos preocupados por discernir, con distinto grado de sistematicidad y coherencia, lo que es de lo que no es, qué hay y qué no, los predicados que valen y los que no se admiten. Lo que de manera esquemática e incompleta se puede enlistar como ciencia, economía, derecho, género, historia, etc., son todas ellas posibilidades ónticas - aunque privilegiadas- de desarrollo discursivo, esto es, opciones de discernimiento óntico en que se define "qué cosas son y qué son esas cosas" (Martínez Marzoa, 1989, p. 33). Por ejemplo: qué enunciados acerca del mundo son verdaderos, qué sistemas administrativos de una sociedad favorecen su crecimiento en términos de bienes materiales, qué actividades son sancionadas por un estado como justas o reprobables, qué perfiles sexuales se institucionalizan y operan en una cultura, qué eventos acontecieron efectivamente en un pasado, etc.

Que sean discursos ónticos significa que proceden con relativa seguridad acerca del ser, validez o consistencia de las cosas que tratan, o sea, caminan seguros con respecto a la quididad del "qué" (puesto que para discernir "qué es" y "qué no es" se presupone en cualquier caso "en qué consiste ser" [Martínez Marzoa, 1996, p. 89]). Mas esta relativa seguridad en su proceder no es ninguna ingenuidad reprochable, sino que resulta constitutiva del discurso óntico mismo. Alguna vez lo advirtió Husserl: para las ciencias, el problema de su validez es enigmático por principio (Husserl, 2009, p. 24). Lo que significa que "la ciencia no tiene el problema de en qué consiste ella misma o de en qué consiste su propia validez" (Martínez Marzoa, 1999, p. 20). Digámoslo así: la ciencia está exenta de filosofar (¿será por eso que la ciencia no piensa?), los discursos ónticos están dispensados de la pregunta ontológica - precisamente porque para haber lo primero tiene que omitirse lo segundo. Por eso Heidegger escribió que la ontología, entendida como ciencia del ser del ente, sólo "externamente" se forma "de un modo semejante a teología, biología, sociología, nombres que se traducen por ciencia de Dios, de la vida, de la sociedad" (Heidegger, 2012, p. 48), ya que "internamente" no es ciencia alguna, al menos no en el sentido de una ciencia positiva.

Ahora bien, esto de ninguna manera significa que la filosofía esté o pueda estar al margen de los discursos ónticos. Pues según se ha dicho repetidamente, sólo puede 
haber filosofía donde a la vez haya algo que interrogar a propósito de su ser, validez o consistencia. Es decir, donde a la vez haya un asunto en litigio: determinados sistemas de verdad, de distribución de bienes, órdenes de justicia o de institución sexual, un pasado contado, etc. Y por ello puede haber filosofía de cualquier cosa, pero al cabo de alguna: epistemología, filosofía de la economía o del derecho, teoría queer, filosofía de la historia, etc. ${ }^{11}$

Con todo, entiéndase bien que estas diversas posibilidades de discurso ontológico no equivalen a la oferta académica de los programas universitarios, sino a ámbitos de lo ente. Y asimismo, entiéndanse no como aquello que hacen mejor ni exclusivamente aquellos "filósofos de...", sino como lo que alcanza cualquiera que, en efecto, piense. Cuestión aparte la de si sean "Sólo unos pocos / pero de acuerdo / en lo solitario / de lo único uno, / de lo mismo: / sólo ellos escuchan el lenguaje / de los lenguajes" (Heidegger, 2010, p. 279).

\section{A modo de conclusión}

Hay una muy compleja amalgama de problemas que se derivan de la manera en que Heidegger caracteriza la ontología. En este estudio me he detenido en dos: su objeto y su condición. A propósito del objeto, he explicado que la ontología está concernida por el ser del ente. Para tratar a su objeto auténticamente -es decir, conservándolo en su carácter- la reflexión debe cuidarse de no confundirlo con lo ente. Por eso, al plantear la cuestión ontológica la filosofía debe evitar responder con "esto, lo otro, o lo de más allá", y en cambio persistir en lo absolutamente diferente de lo ente, diferencia que designan por igual el ser y la nada. Pero también se vio que, a pesar de su diferencia, el ser siempre es del ente, la ontología es relativa a lo óntico, la filosofía es una posibilidad que emerge de las cosas al tiempo en que se ven frustradas. Tal es la doble condición de la ontología: que arranca de la siempre presupuesta determinación de las cosas (del siempre operativo juego en el que cada cosa es lo que es), pero también que tal arranque supone que la cosa devenga problemática (que el juego se interrumpa).

Por todo ello es que, si en general hubiera que caracterizar en unas cuantas palabras la filosofía de Martin Heidegger, podría decirse que procura, a través de muy diversos

11 En una entrevista aún inédita a cargo de Pilar Gilardi y Delmiro Rocha, Arturo Leyte presenta algunas ideas que explican el sentido de que filosofía — heideggerianamente comprendida — sólo puede haberla ahí donde a su vez haya algo que interrogar acerca de su ser. Ahora sólo recupero lo siguiente: "Se puede decir que, propiamente, en Heidegger no hay 'tema', como lo he sostenido en alguno de mis escritos, pero lo que han dicho otros sí es condición de su propio trabajo, tan ineludible, que sin esa lectura no habría filosofía de Heidegger. [...] En la medida en que Heidegger hace de la lectura de otros filósofos condición de su propio trabajo, lo que estoy sugiriendo de alguna manera, y que además es una consecuencia inevitable, es que Heidegger no es original. Puede ser específico, pero no original, en el sentido de que no descubre nada, sino que redescubre algo". Agradezco a la profesora Gilardi el haber tenido a bien permitirme acceso al manuscrito que actualmente se encuentra en prensa para publicarse en La apropiación de Heidegger, coeditado por Bonillas Artigas y la BUAP. 
caminos, el planteamiento de una forma no-positiva de investigación ontológica. Esto es, se esfuerza en preguntar por el ser (consistencia o validez), malogrando una y otra tentativa de respuesta, una y otra tentativa de dar por concluido el desarrollo de la pregunta. Quizá tal intención estuviera de fondo en lo que Heidegger decía a su alumno Gadamer: "Sí, sí; pero esto es óntico y no ontológico" (Gadamer, 2003, p. 355).

El problema que se ha desarrollado sobre la relación inherente de la filosofía con la cosa, expresa, aunque en un vocabulario poco común en Heidegger, el aspecto hermenéutico de su fenomenología. Pues si se asume que no hay cosa sin la posibilidad de que sea dicha, y que la cuestión del ser arranca de un encontrarse ya en todo caso entre las cosas, entonces "esto es sinónimo de que siempre ya [se] escucha un decir" (Martínez Marzoa, 1999, p. 46), "que el pensador es el que escucha el decir, y por eso es precisamente él no el dicente, sino el hermeneuta” (Martínez Marzoa, 1999, p. 43). Y es que no es coincidencia el que Sócrates no sea quien nombra, y en cambio sea quien se obstina en preguntar. Al cabo, quien pregunta es aquel dispuesto a cierto tipo de escucha. Y la escucha es el carácter fundamental de la hermenéutica.

Después de todo lo dicho, podría resultar incierto la clase de porvenir que depara a la ontología, siendo que no se trata de una ciencia positiva y por tanto queda en entredicho la posibilidad de su correcto encauce. Contra lo que pensó Kant, no hay camino seguro para la filosofía. Ella, anotó Heidegger, no tiene la misión de ahorrar a las generaciones venideras la preocupación de plantearse cuestiones; "la filosofía es lo que puede ser sólo cuando es de su 'tiempo"' (Heidegger, 2008, p. 38). Y es que no hay progreso en la filosofía; sólo hay regreso. Es decir, hay la reiteración de una misma pregunta, aunque siempre una reiteración hermenéutica. El futuro de la ontología heideggeriana está en la posibilidad de que se la reinterprete productivamente. El porvenir de Heidegger se halla en la potencia de las sucesivas apropiaciones de su pensamiento. Hay filosofías que no admiten epígonos, pero en cambio celebran a quien de ellas abreva por alguna necesidad auténtica.

\section{Referencias}

Adrián Escudero, J. (2009). El lenguaje de Heidegger: Diccionario filosófico 1912-1927. Barcelona: Herder.

Blattner, W. (2007). Ontology, the A Priori, and the Primacy of Practice. En S. Crowell, \& J. Malpas (Eds.), Transcendental Heidegger (pp. 10-27). California: Stanford University Press.

Chame, S. (2017). La ontología negativa en las filosofías socráticas y sus proyecciones interepocales. Eidos, 27, 39-69. http://dx.doi.org/10.14482/eidos.27.8119

Dilthey, W. (2000). Dos escritos sobre hermenéutica. El surgimiento de la hermenéutica y los Esbozos para una crítica de la razón histórica (A. Gómez Ramos, Trad.). España: Istmo. 
Gadamer, H. G. (2003). Los caminos de Heidegger (A. Ackermann Pilári, Trad.). Barcelona: Herder. Gilardi, P. (2013). Heidegger: la pregunta por los estados de ánimo (1927-1930). México D. F.: Bonilla Artigas.

Heidegger, M. (1988). Identidad y diferencia (H. Cortés \& A. Leyte, Trads.). Barcelona: Anthropos. Heidegger, M. (2000). Los problemas fundamentales de la fenomenología (J. J. García Norro, Trad.). Madrid: Trotta.

Heidegger, M. (2002). Nietzsche I (J. L. Vermal, Trad.). Barcelona: Destino. Heidegger, M. (2004). Lógica. La pregunta por la verdad (A. Ciria, Trad.). España: Alianza.

Heidegger, M. (2006). Prolegómenos para una historia del concepto de tiempo (J. Aspiunza, Trad.). Madrid: Alianza.

Heidegger, M. (2007a). Hitos (H. Cortés \& A. Leyte, Trads.). Madrid: Alianza.

Heidegger, M. (2007b). Los conceptos fundamentales de la metafísica. Mundo, finitud, soledad (A. Ciria, Trad.). Madrid: Alianza.

Heidegger, M. (2008). Ontología. Hermenéutica de la facticidad (J. Aspiunza, Trad.). Madrid: Alianza. Heidegger, M. (2010). Pensamientos poéticos (A. Ciria, Trad.). Barcelona: Herder.

Heidegger, M. (2012). Ser y tiempo (J. E. Rivera, Trad.). Madrid: Trotta.

Husserl, E. (1999). Investigaciones lógicas, I (M. G. Morente y J. Gaos, Trads.). España: Alianza. Husserl, E. (2009). La filosofía, ciencia rigurosa (M. G. Baró, Trad.). Madrid: Encuentro.

Law, David R. (2000). Negative theology in Heidegger's Beiträge zur Philosophie. International Journal for Philosophy of Religion, 48(3), 139-156. https://doi. org/10.1023/A:1026569031915

Leyte, A. (2005). Heidegger. Madrid: Alianza.

Martínez Marzoa, F. (1989). Releer a Kant. Barcelona: Anthropos.

Martínez Marzoa, F. (1996). Ser y diálogo: Leer a Platón. Madrid: Istmo.

Martínez Marzoa, F. (1999). Heidegger y su tiempo. Madrid: Akal.

Martínez Marzoa, F. (2000). Historia de la filosofía antigua. Madrid: Akal.

Platón. (1871). Obras completas. Tomo 1 (P. de Azcárate, Trad.). Madrid: Medina y Navarro.

Platón. (1988). Diálogos 5. (M. I. Santa Cruz, Á. V. Campos, N. L. Cordero, Trads.). Madrid: Gredos. Vigo, A. (2008). Arqueología y aleteiología. Buenos Aires: Biblos. 
